\title{
A Convenient Way to do Valgus Osteotomy for Neglected Fracture Neck of Femur
}

\author{
Bansal $\mathrm{P},{ }^{1}$ Singhal $\mathrm{V},{ }^{2}$ Lal $\mathrm{H},{ }^{2}$ Mittal $\mathrm{D},{ }^{2}$ Arya $\mathrm{RK}^{2}$
}

\author{
Department of Orthopaedics \\ ${ }^{1}$ E.S.I Hospital, Manesar, Haryana \\ ${ }^{2}$ Dr. Ram Manohar Lohia Hospital \\ New Delhi \\ India \\ Corresponding Author \\ Pankaj Bansal \\ Department of Orthopaedics \\ E.S.I Hospital, Manesar \\ Haryana, India \\ Email: bansalpankajj@gmail.com
}

\section{Citation}

Bansal P, Singhal V, Lal H, Mittal D, Arya RK. A convenient Way to do Valgus Osteotomy for Neglected Fracture Neck of Femur. Kathmandu Univ Med J 2013;42(2):147151.

\begin{abstract}
Background

Neglected fracture of neck of femur in young adults is a major problem in developing countries. Existing treatment options varies from osteotomy to various graft techniques (muscle pedicle, vascularized and nonvascularized fibula etc.). There is paucity of literature regarding the use of double angle barrel plate and hip screw in such cases. We conducted a prospective longitudinal observational study with displaced, neglected fracture neck of femur in young adults and compared the results with literature.
\end{abstract}

\section{Objectives}

The aim of this study was to determine feasibility and effectiveness of $120^{\circ}$ double angle barrel plate and hip screw fixation in neglected fracture neck of femur. Effectiveness of fixed 30 degree closed wedge osteotomy in neglected fracture neck of femur.

\section{Methods}

Thirty cases of neglected (more than three weeks) femoral neck fracture (Pauwel II and III) of age 20-60 years were included in the study conducted at Postgraduate Institute Of Medical Education and Research, Dr. Ram Manohar Lohia Hospital, New Delhi, India in year 2004-06. Average age of the patient was 35.4 years (range, 22 yrs-55yrs). In all cases internal fixation was done by $120^{\circ}$ double angle barrel plate and hip Screw. At the end of follow-up, results were evaluated according to Askin Bryan Criteria and Harris-hip score.

\section{Results}

Union was achieved in 28 of 30 patients. Two patients that went into nonunion were later treated with hemireplacement arthroplasty. According to Askin Bryan Criteria at the end of study, 35\% patients had excellent results, $50 \%$ patients had good results. Minimum follow-up in our study was 12 months and maximum was five years.

\section{Conclusion}

This study validates the use of double angled screw plate configuration for successful outcome in patients with neglected fracture neck of femur. Valgus osteotomy is also technically easy operation in hands of average trauma surgeon with the use of a fixed angle plate and hip screw.

\section{KEY WORDS}

Fracture, neck of femur, neglected, osteotomy

\section{INTRODUCTION}

Fracture of neck of femur is still the unsolved fracture and neglected fracture neck of femur still poses a greater dilemma from treatment point of view. In developing countries, late and neglected presentation of femoral neck fractures is common because of many socio-economic reasons like local bone setters, lack of awareness and transport etc. Sandhu defined neglected fractures as those fractures that are left untreated for three weeks. ${ }^{1}$
Precarious blood supply, difficulty in reduction, strong muscle force, flow of synovial fluid, no cambium layer in periosteum and amount of posterior communition are the main reasons for nonunion and avascular necrosis. ${ }^{2}$ Neck resorption, avascular necrosis, increased fracture gap, osteoporosis and sclerosis and small femoral head fragment make neglected fractures a bigger challenge. ${ }^{1}$ 
Surgical treatment in neglected femoral neck fractures in young adults includes muscle pedicle grafting, vascularized bone grafting, non-vascularized fibula grafting and osteotomies. Valgus osteotomy has been used to treat nonunion and neglected fracture of femoral neck. Most surgeons use double angled blade plate for internal fixation after osteotomy..$^{3-6}$ In internal fixation by blade plate, at times the blade may displace the fracture fragments and minimal change in the direction of blade may change the direction of plate anterior or posterior to the shaft of femur. Valgus osteotomy fixation with double angle blade plae is also technically demanding. Because of these complications with double angle blade plate we used $120^{\circ}$ double angle barrel plate and hip Screw.

Very little literature is available is available to show the effectiveness of 30 degree fixed closing wedge valgus osteotomy valgus osteotomy stabilized by fixed angle double barrel plate with dynamic hip screw (DHS) in neglected fractures of femoral neck. ${ }^{7,8}$

This study was aimed at assessing the role of double angled barrel plate with DHS implant for fixing the valgus osteotomy and hence evaluating the effectiveness of 30 degree fixed closing wedge valgus osteotomy in treating neglected fracture neck of femur.

\section{METHODS}

We present a prospective case study of 30 patients with displaced, neglected fracture neck of femur treated with valgus osteotomy. Average age of the patient was 35.4 years (range, 22yrs-55yrs). Seventy percent patients were males and $30 \%$ patients were females. Average interval between injury and operation was 17.3 weeks (range, 4 to 30 weeks). Two cases had associated injuries. One case had associated fracture of distal end of radius and another had fracture of ipsilateral superior and inferior pubic rami. All the cases were between 20 to 60 years of age and otherwise medically fit expect two patients. Out of these two patients one patient had post polio residual paralysis of the affected limb and another one had hypothyroidism. All the fractures were classified according to Pauwels' and Garden. There were six Pauwels' type II and 24 type III cases. By the Garden classification 10 were stage three and 20 were stage four.

This study was conducted at Postgraduate Institute Of Medical Education and Research, Dr. Ram Manohar Lohia Hospital, New Delhi, India in year 2004-06. Displaced neglected fracture of femoral neck in the age group of 20-60 years. Patients with Pauwels' type I fracture, pathological fracture, and any preexisting hip disorders like osteoarthritis, tuberculosis of hip joint, rheumatoid arthritis, ankylosing spondylitis etc or with bleeding diathesis were excluded from the study.

Preoperatively detailed workup of the patients included an anteroposterior radiographs of pelvis with both hip in 15 degree internal rotation and lateral radiographs. Pauwels' angle between fracture line of the distal fragment and horizontal imaginary line was measured. Preoperatively templating was done to define the steps of surgery and calculate the point of entry of DHS (Fig 1a,b). We aimed at removing a fixed wedge of 30 degrees. Preoperatively no bone scan/Magnetic Resonance Imaging (MRI) was not performed, since patients belonged to low socioeconomic status and also presence of avascular necrosis (AVN) did not change the indication of osteotomy. ${ }^{3,4,9}$

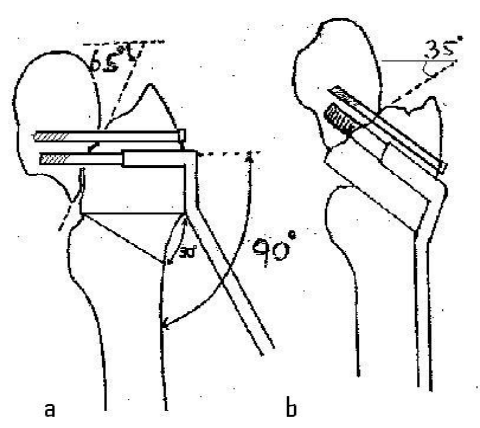

Figure 1.(a) Diagram showing fixation with derotation screw, calculation of entry point for dynamic hip screw. (b) Diagram showing removal of fixed wedge of $\mathbf{3 0}$ degree and change in the fracture angle after osteotomy.

Preoperatively skeletal traction was used in 10 patients to decrease shortening.

Closed reduction of femoral neck fracture was done. ${ }^{10}$ Operative procedure was done on a standard fracture table under image intensifier control. Lateral approach was taken to expose the upper part of femur. Firstly a cannulated cancellous derotation screw was inserted through the neck into superior aspect of the neck. Insertion of DHS was then performed in a routine manner using a 90-degree angle guide. A 120-degree fixed double-angled barrel plate was placed over DHS and site of osteotomy was marked at the level of angle of double angle barrel plate by drilling a transverse $\mathrm{K}$ wire at that level under $\mathrm{C}$-arm. Linear transverse osteotomy was done firstly proximally and then angled cut was made distally with the help of metallic goniometer. The osteotomy was completed by oscillating bone saw. Predetermined size of wedge was removed i.e. 30 degrees in all the cases. Closure of the osteotomy was performed by abducting the limb. The barrel plate was fixed with cortical screws and compression screw was inserted in the hip lag screw to compress the fracture site as much as feasible. Wound was closed in layers after leaving suction drain.

Postoperative protocols- Postoperative non weight bearing crutch walking was allowed as soon as the patients became pain free, partial weight bearing at five to seven weeks and full weight bearing was allowed according to progress of union at osteotomy as well as fracture site. Patients were followed at 2, 6, 10, 14, 18, 24 weeks and then every three 
month till one year and after that at six-monthly intervals.

Minimum duration of follow-up in our study was 12 months and maximum duration was five years. Results were evaluated according to Askin Bryan Criteria (Table 1) and Harris-hip score. ${ }^{11,12}$

Our study had been approved by the ethical Committee of the institution. All patients gave their consent prior to their inclusion in the study.

\section{Table 1. Askin Bryan Criteria.}

\begin{tabular}{|l|l} 
Excellent & $\begin{array}{l}\text { Full range of movements and strength, little or no pain and } \\
\text { essentially normal appearing radiographs }\end{array}$ \\
Good & $\begin{array}{l}\text { Some limitation of motion, mild discomfort and mild joint } \\
\text { space narrowing }\end{array}$ \\
Fair & $\begin{array}{l}\text { Some limitation of motion and moderate pain with degen- } \\
\text { erative changes or aseptic necrosis }\end{array}$ \\
Poor & $\begin{array}{l}\text { Severe restriction of function and pain requiring salvage } \\
\text { procedure }\end{array}$
\end{tabular}

\section{RESULTS}

Union is defined as bridging of three of four cortices and disappearance of fracture line on the plain radiographs for a patient who is able to bear full weight without pain. ${ }^{6}$ Fracture united in 28 patients (Fig 2a,b , Fig 3a,b and Fig $4 a, b)$. Average time for fracture union was 18.6 weeks (range, 14-24 weeks). Two cases went into nonunion. In
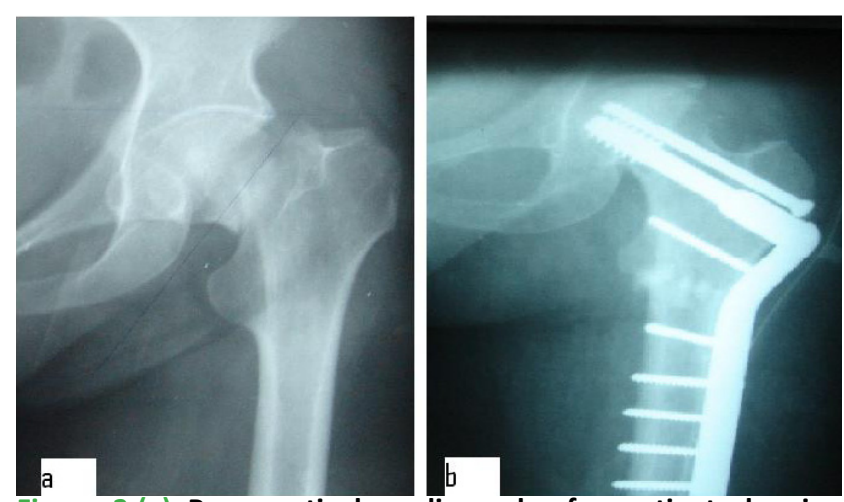

Figure 2.(a) Preoperatively radiograph of a patient showing fracture neck of femur. (b) Postoperative radiograph of same patient at 3 years, showing union of fracture and osteotomy site.

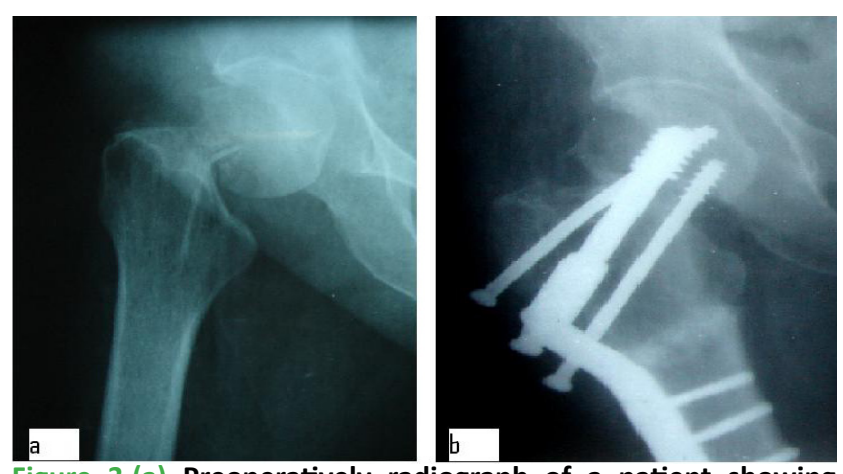

Figure 3.(a) Preoperatively radiograph of a patient showing fracture neck of femur. (b) Postoperative radiograph of same patient at $\mathbf{5}$ years, showing union of fracture and osteotomy site and bending of derotation screw.

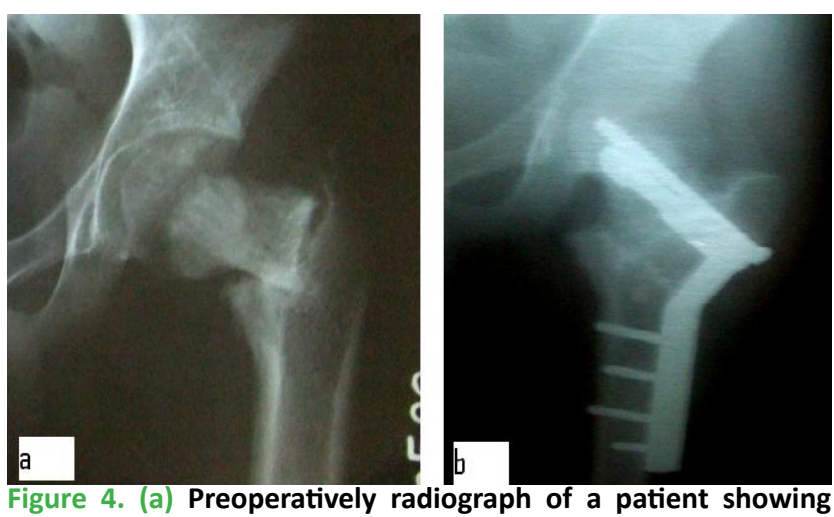

fracture neck of femur. (b) Postoperative radiograph of same patient at 3 years, showing union of fracture and osteotomy site.

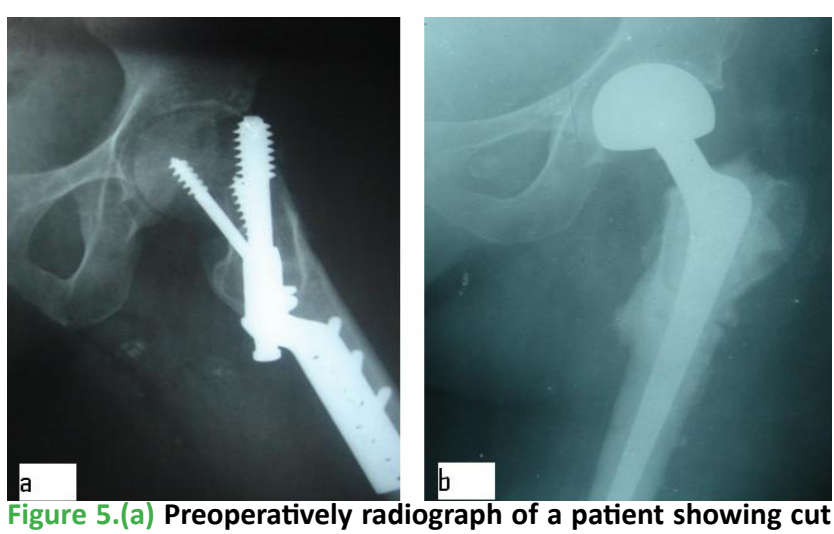

through of the implant. (b) Radiograph of the same patient after hemireplacement arthroplasty.

both of these patients' DHS cut through the femoral head. Both of these patients were of age around 55 years and female. Successful hemiarthroplasty was performed in both of cases subsequently without any difficulty (Fig $5 a, b)$. Placement of hip screw was central in 18 patients and inferior in 12 patients. In one case derotation screw got bent (Fig 3b); the most probable reason for screw bending was early full weight bearing by the patient. Patient was advised to delay full weight bearing and fracture united uneventfully. All osteotomy sites united and the average time of union of osteotomy site was 9.7 weeks (range, 10 -14 weeks). Preoperatively limb length shortening was present in all cases. Postoperatively limb length equalization was achieved in 25 cases. The remaining five patients had average postoperative shortening of $1.4 \mathrm{~cm}$ (range, $1-2 \mathrm{~cm}$ ) for which shoe raise was advised. Hip assessment was done using the Harris hip score and Askin Bryan Criteria. By Askin Bryan criteria $33.3 \%$ patients had excellent results, $56.6 \%$ patients had good results, 3.3\% had fair results and $6.6 \%$ had poor results. By Harris hip score $26.6 \%$ patients had excellent results, $63.3 \%$ patients had good results, $3.3 \%$ had fair results and $6.6 \%$ had poor results There were no wound or thrombosis related complications. 


\section{DISCUSSION}

According to King, chances of nonunion of femoral neck fracture are more in fractures treated after three weeks. ${ }^{13}$ Similar results were reported by Barns et al, who reported incidence of nonunion was as high as $50 \%$ if fracture to treatment duration was more than one week. ${ }^{14}$ So internal fixation with only cancellous screws or plain osteosynthesis is not sufficient for neglected fractures in young adults; and may require supplementation with graft, osteotomy etc. According to Sandhu et al, various changes occurs in the region of neglected fracture like smoothening of fracture margins, absorption of neck of femur, increase in the gap between fragments, decrease in size of proximal fragment and osteonecrosis. ${ }^{1}$ These factors increase the nonunion rates appreciably if treatment of fracture neck femur is delayed. Any method for treatment of displaced femoral neck neglected fracture should ideally meet the following basic objective to achieve union at fracture site: Elimination of shearing forces acting at fracture site and converting them into compressive forces, provide mechanically stable fixation, preserve remaining vascularity, allow revascularization of femoral head and facilitate early mobilization of the patient.

The biomechanical principle behind Valgus osteotomy is that it converts shearing forces into compressive forces by changing the fracture inclination. Valgus osteotomy with fixation by double angle blade plate is a traditional method for the treatment of nonunion and for neglected fracture of femoral neck. Fixation by double angle blade plate is a technically demanding procedure and blade plate may displace the fracture fragments. Dynamic compression screw, which is routinely used for intertrochanteric fractures, provides a technically simple means of fixation for valgus osteotomies in the treatment of femoral neck nonunion and every orthopaedic surgeon is well acquainted with its use. An added advantage over blade plate is, it provides compression at the fracture site. The biological advantage of valgus osteotomy is an increase in blood flow after osteotomy which increases the chances of union. According to various reports AVN is not a contraindication for valgus osteotomy. ${ }^{3,49}$

Literature showed good results of treatment of nonunion and of neglected neck femur with valgus osteotomy (Table 2). The largest series is by Marti et al, who reported results of osteotomy in 50 patients of fewer than 70 years age. ${ }^{3}$ Union occurred in $86 \%$ of patients. Anglen reported results of osteotomy in 13 patients. ${ }^{4}$ Union occurred in all patients. Although there is a paucity of literature regarding the use of double angle barrel plate, our study showed comparable results (Table 2).

In our study cut through of the DHS happened in two cases, hemireplacement arthroplasty was performed in both cases and both patients did not have any complain at final follow-up. Both ofthese patients were of age around 55 years and female. Most probably osteoporosis was the
Table 2. Comparison of studies of valgus osteotomy.

\begin{tabular}{|c|c|c|c|c|c|}
\hline Author & $\begin{array}{l}\text { Total } \\
\text { number } \\
\text { of pa- } \\
\text { tients }\end{array}$ & $\begin{array}{l}\text { Time } \\
\text { interval } \\
\text { between } \\
\text { injury and } \\
\text { treatment }\end{array}$ & $\begin{array}{l}\text { Implant } \\
\text { for used } \\
\text { treatment }\end{array}$ & Union & $\begin{array}{l}\text { Significant } \\
\text { complica- } \\
\text { tion }\end{array}$ \\
\hline $\begin{array}{l}\text { Marti et } \\
\text { al (1989) }\end{array}$ & 50 & $2-60 \mathrm{mths}$ & $\begin{array}{l}\text { Double } \\
\text { angle } \\
\text { blade plate }\end{array}$ & $86 \%$ & $\begin{array}{l}\text { Technical } \\
\text { difficulties } \\
\text { in } 6 \text { cases }\end{array}$ \\
\hline $\begin{array}{l}\text { Anglen } \\
\text { (1997) }\end{array}$ & 13 & 4-54 wks & $\begin{array}{l}\text { Double } \\
\text { angle } \\
\text { blade plate }\end{array}$ & $100 \%$ & $\begin{array}{l}\text { Avascular } \\
\text { necrosis(2) }\end{array}$ \\
\hline $\begin{array}{l}\text { Kalra and } \\
\text { Anand } \\
\text { (2001) }\end{array}$ & 20 & $1-12 \mathrm{mths}$ & $\begin{array}{l}\text { Double } \\
\text { angle } \\
\text { blade plate }\end{array}$ & $85 \%$ & $\begin{array}{l}\text { Avascular } \\
\text { necrosis(2) }\end{array}$ \\
\hline $\begin{array}{l}\text { Purthi } \\
\text { (2004) }\end{array}$ & 28 & $3->12 w k s$ & $\begin{array}{l}\text { Double } \\
\text { angle } \\
\text { blade plate }\end{array}$ & $88 \%$ & $\begin{array}{l}\text { Implant cut } \\
\text { through(2) }\end{array}$ \\
\hline $\begin{array}{l}\text { Hartfold } \\
(2005)\end{array}$ & 8 & 5-14mths & Hip screw & $85 \%$ & - \\
\hline $\begin{array}{l}\text { Abdul et } \\
\text { al (2009) }\end{array}$ & 16 & 3-76wks & $\begin{array}{l}\text { Double } \\
\text { angle } \\
\text { blade plate }\end{array}$ & $87 \%$ & $\begin{array}{l}\text { Implant cut } \\
\text { through(2) }\end{array}$ \\
\hline $\begin{array}{l}\text { Current } \\
\text { study }\end{array}$ & 30 & 4-30wks & $\begin{array}{l}\text { Double } \\
\text { angle } \\
\text { blade plate }\end{array}$ & $99 \%$ & $\begin{array}{l}\text { Implant cut } \\
\text { through(2) }\end{array}$ \\
\hline
\end{tabular}

cause of implant failure. According to Garden, osteoporosis decreases the quality of internal fixation. ${ }^{15}$ We removed a fixed wedge of 30 degrees in all the cases. This made our surgery simpler as valgus angles more than 30 degree increases chances of AVN as pointed out by Frank and Rinaldi. According to Rinaldi et al, any value of intertrochanteric wedge of more than 30 degree necessary to achieve the ideal re-orientation of fracture line is inadvisable because it would create an excessive degree of valgus which in turn would subject the femoral head to load bearing stresses which would increase the hazard of segmental necrosis. ${ }^{16}$ According to Frank et al, extreme rotatory or valgus malposition caused complete interruption of blood supply of femoral head and moderate valgus caused interrupted blood supply in adduction. ${ }^{17}$ We agree with Anglen and Hartford et al, which in spite to position all Pauwels' type III fracture to type I fracture, achieved good results. ${ }^{4,18}$ So it's not worthwhile to make osteotomy angles more than 30 degrees. In our series all Pauwels' type III fractures were united. However, major drawback of our series was that our follow-up was limited to maximum of five years during which there was no incidence of hip osteoarthritis after valgus osteotomy and we cannot comment on arthritis developing from increased joint reactive forces after that. But Marti et al reported that even with average follow-up of seven years, chances of degenerative changes are very less.

\section{CONCLUSION}

This study brings out some interesting facts. First, neglected fracture do unite with a 30 degree fixed closing wedge valgus osteotomy; it also makes fixation with a 120 degree 
double angle barrel plate easier. Second, non of it surgeon can perform the procedure, as DHS fixation is familiar to every surgeon. Third, removing a fixed angle of wedge is easy and safe, with minimal preoperative planning and peroperative technicalities in the procedure. Fourth, we did not experience any difficulty in doing arthroplasty procedure in two of our failed patients. One could negotiate the broach into the femoral canal for the stem to go in. This fixed angle alters the hip biomechanics to a lesser extent.

\section{REFERENCES}

1. Sandhu HS, Sandhu PS, Kapoor A. Neglected fractured neck of the femur: a predictive classification and treatment by osteosynthesis. Clin Orthop 2005;431:14-20.

2. Canale ST. Campbell's operative orthopaedics. 10th edition (Vol 3). UK: Mosby;2005:2909.

3. Marti RK, Scholler HM, Raavmakers EL. Intertrochanteric osteotomy for nonunion of femoral neck. J Bone Joint Surg [Br] 1989;71(5):782787.

4. Anglen JO. Inter-trochanteric osteotomy for failed Internal fixation of femoral neck fracture. Clin Orthop 1997;341: 175-82.

5. Kalra $M$, Anand. Valgus intertrochanteric osteotomy for neglected femoral neck fractures in young adults. Int Orthop 2001;25(6):363366.

6. Magu NK, Rohilla R, Singh R, Tater R. Modified Pauwels' intertrochanteric osteotomy in neglected femoral neck fracture. Clin Orthop 2009;467(4):1064-73.

7. K.K. Pruthi, H. Chandra, R.K. Goyal, and V.P. Singh. Repositioning osteotomy with dynamic hip screw with 120 o double angled barrel plate fixation in fracture neck femur. Ind J Orthop 2004;38:92-95.

8. Khan AQ, Khan MS, Sherwani MK, Agarwal R. Role of valgus osteotomy and fixation with dynamic hip screw and $120^{\circ}$ double angle barrel plate in the management of neglected and ununited femoral neck fracture in young patients. J Orthop Traumatol 2009;10(2):71-8.

9. Ballmer FT, Ballmer PM, Baumgaertel F, Mast JW, Ganz R. Pauwels osteotomy for nonunion of the femoral neck fracture. Orthop Clin North Am 1990;21:759-767.
10. Whitman R. The abduction method considered as the exponent of a treatment for all forms of fracture of the hip in Accord with surgical principals. Am J Surg 1933;21:335-344.

11. Askin SR, Bryan RS. Femoral neck fractures in young adults. Clin orthop 1976;114:259-264.

12. Harris WH. Traumatic arthritis of the hip after dislocation and acetabular fractures: Treatment by mold arthroplasty. An end result study using a new method of result evaluation. J Bone Joint Surg 1969;51a:737-765.

13. King T. Closed reduction for intracapsular fracture of the neck of the femur. Br J Surg 1939;26:721-48.

14. Barns JT, Brown JT, Garden RS, Nicoll EA. Subcapital fractures of the femur: a prospective study. J Bone Joint Surg 1976;58B:2-24.

15. Garden RS. Stability and union in subcapital fractures of the femur. $J$ Bone Joint Surg [Br] 1964;46B: 630-647.

16. Rinaldi E, Marenghi $P$, Negri V. Osteosynthesis with valgus osteotomy in the primary treatment of subcapital fractures of the neck of femur. Ital J Orthop Traumatol 1984;10(3): 313-320.

17. Frank B.Smith. Effects of rotatory and valgus malpositions on the blood supply of femoral head. J Bone Joint Surg [Am] 1959;41(5):800815.

18. Hartford JM, Patel A, Powell J. Intertrochanteric osteotomy using a dynamic hip screw for femoral neck nonunion. J Ortho Trauma 2005;19:329-333. 